\title{
LITERATURA E TERRITORIALIDADE NA FRONTEIRA BRASIL/BOLIVIA: UM ESPAÇO DO SER FRONTEIRIÇO
}

\author{
Literature and territoriality in the Brazil/Bolivia border: \\ a space of frontier being \\ Literatura y territorialidade en la frontera Brazil/Bolívia: \\ un espacio del ser fronterizo
}

\author{
Tarissa Marques Rodrigues dos Santos* \\ Lucilene Machado Garcia Arf* \\ *Mestranda em Estudos Fronteiriços pela UFMS - tarissamarques@gmail.com \\ **Professora Doutora do Programa de Pós-Graduação Mestrado em Estudos Fronteiriços pela \\ UFMS - lucilenemachado@terra.com.br
}

Recebido em 17/02/2020. Aceito para publicação em 17/03/2020.

Versão online publicada em 05/05/2020 (http://seer.ufrgs.br/paraonde)

\section{Resumo:}

Este artigo propõe a reflexão da literatura como um meio de aproximação de culturas que circulam no território fronteiriço Brasil-Bolívia, de como é vista a fronteira e como sentir-se parte dela. $O$ uso da literatura serve tanto para ensinar a ler e a escrever quanto para formar culturalmente um indivíduo. Para dar sustentação teórica a este estudo, escolheu-se alguns conceitos essenciais acerca de território, territorialidade e fronteira a partir de autores como Raffesttin (1993), Saquet (2007) Nogueira (2007), Guhl (1991) e Hissa (2002), com o fim de colocar em debate a importância da literatura como construção de identidades de um povo e sensibilizar a comunidade com relação ao papel social de cada um na espacialização fronteiriça.

Palavras-chave: Literatura. Fronteira.Identidade.Território.Espacialização.

\begin{abstract}
:
This article proposes to reflect the literature as a means of approaching cultures that circulate in the border territory of Brazil-Bolivia, how the frontier is seen and how to feel part of it. The use of literature serves both to teach reading and writing and to form a culturally individual. To give theoretical support to this study, we chose some essential concepts about territory, territoriality and border from authors such as Raffesttin (1993), Saquet (2007) Nogueira (2007) e Guhl (1991). In order to put into debate the importance of literature as the construction of identities of a people and sensitizing the community in relation to the social role of each in the border spatialization.
\end{abstract}

Key-words: Literature. Border. Identity. Territory. Spatialization.

\section{Resumen:}

Este artículo propone reflejar la literatura como un medio para acercarse a las culturas que circulan en el territorio fronterizo de Brasil-Bolivia, cómo se ve la frontera y cómo sentirse parte de ella. El uso de la literatura sirve tanto para enseñar a leer y escribir como para formar un individuo cultural. Para dar apoyo teórico a este estudio, elegimos algunos conceptos esenciales sobre territorio, territorialidad y frontera de autores como Raffesttin (1993), Saquet (2007) Nogueira (2007) e Guhl (1991). Con el fin de poner en debate la importancia de 
la literatura como la construcción de identidades de un pueblo y sensibilizar a la comunidad en relación con el papel social de cada uno en la espacialización fronteriza.

Palabras-clave: Literatura. Frontera. Identidad. Territorio. Espacialización.

\section{Introdução}

A literatura possui muitas finalidades, lemos para deleitar, espairecer, também para nos assegurar de tais informações e ampliar nossos horizontes. $E$ como leitores, somos tocados pelas experiências que a leitura carrega sobre si, pois interagimos com o que lemos, e muitos tipos de leituras rememoram vivências pessoais e nos ajudam a refletir sobre a nossa identidade e também como constructo social.

A literatura é linguagem e,tanto quanto, cumpre juntamente com outras artes, um papel comunicativo na sociedade, podendo tanto influenciar o público quanto ser influenciada por ele. A literatura nos permite "viver" outras vidas, sentir, outras emoções e sensações, e nos oferece determinada trégua dos problemas cotidianos a medida que descortina o espaço do sonho e da fantasia. Como proferiu Roland Barthes (1977), "a literatura assume muito saberes", e são esses saberes enraizados na cultura local que contribuem para moldar a identidade dos que "transitam" na fronteira oeste de Brasil-Bolívia.

Quando falamos em fronteira convém destacar que é um conceito bastante confundido com a noção de limite. Considera-se, nesses casos, que a fronteira é uma linha imaginária, um marco histórico ou geográfico que separa duas ou mais nações. Para Cássio Eduardo Hissa (2002), o limite aguça a ideia sobre a distância e a separação, enquanto a fronteira estimula a reflexão sobre o contato e a integração. Assinala ainda que a reflexão sobre limites e fronteiras é, também, uma discussão sobre o poder, considerando que fronteiras e limites servem para estabelecer domínios e demarcar territórios.

O limite defende ainda uma noção significativa para a compreensão de território, principalmente aquela noção que aproxima o conceito de território à área de ação dos Estados Nacionais, espaço de exercício das políticas governamentais, da apropriação e das estratégias de proteção das fronteiras. A fronteira é sobre tudo o contato entre o conhecido e o desconhecido, entre nós e os outros, entre a sociedade e a natureza. Estar e viver em espaços de fronteiras pressupõe-se relações distintas e exclusivas, podendo representar importantes relações com o ambiente por meio da convivência.

Cabe destacar, que a fronteira só é realmente entendida quando analisada pela ótica local, pelas pessoas, que ali vivem e se constituem socialmente. José Ricardo Nogueira (2007) em seus estudos sobre as formações das fronteiras, discute o conceito de fronteira como algo percebido e vivido. Os fronteiriços olham a fronteira como a sua morada, onde acontece 0 seu cotidiano, seu ritmo, suas relações de afetividade, afloarando de tal forma como o seu "lugar".

$\mathrm{Na}$ perspectiva desses autores acima citados, a fronteira é entendida

ParaOnde!?, Porto Alegre, v13, n.2, p.196-206, 2020.http://seer.ufrgs.br/paraonde Edição Especial - VII Seminário Internacional de Estudos Fronteriços 
como um lugar de alteridade, particularidade do "eu" e do "outro", um fenômeno social e intercultural e que pode ser estudado levando em consideração, em especial, as relações vivas, humanas, existente dentro desse espaço fronteiriço, ou seja, estudar como se estrutura a zona fronteiriça, como os fronteiriços se organizam e como vivem seu dia a dia dentro de um espaço politicamente descontínuo, com sistemas e normas diferenciadas.

A proposta desse artigo é investigar a literatura como um meio de aproximação das culturas que circulam nesse território fronteiriço, de como ver a fronteira e sentir-se parte dela. Para isso, serão discutidos os conceitos de território e territorialidades, sobretudo nas análises geográficas e contatos de cultura. Na sequência, o conceito de identidade territorial entrelaçado à realidade da fronteira Brasil-Bolívia, apresentando a literatura como fator de humanização entre culturas.

\section{Desenvolvimento}

\section{Território, territorialidade: o espaço do fronteiriço}

Retomando a definição de fronteira, buscando entender essa espaço fornteiriço, observa-se uma evolução que percorre os momentos históricos desde a criação e formação dos territórios. Nogueira (2007,p.29) explica que, etimologicamente, a palavra fronteira é procedente do antigo latim 'fronteria' ou 'frontaria', e apontava inicialmente a parte do território situado "in fronte", isto é, nas margens, expedindo, portanto, uma qualidade e não uma entidade".

Seu significado sempre esteve congruente com algo que está na frente, como sugere a própria etimologia da palavra, o que lembra de imediato um território, suas relações de poder e ordenamento.

Segundo Saquet (2007), a territorialidade não é sinônimo de raízes territoriais, visto que é transportável e dinâmica, como no caso de migrantes que se apropriam de novos territórios e reconstituem suas identidades territoriais em novos espaços. A territorialidade acumula tempo, experiência e é fruto das relações econômicas, políticas e culturais de um local. Souza (2013) acrescenta que no diagnóstico do território, não somente a proporção política é um item a ser ponderado, pois existem outros traços da vida social, que interferem diretamente ou indiretamente sobre esta categoria espacial, como é a situação da cultura e da economia. Ele afirma que:

\footnotetext{
Mais uma vez: o que "define" o território é, em primeiríssimo lugar, o poder. Ou, em outras palavras, o que determina o "perfil" do conceito é a dimensão política das relações sociais [...]. Isso não quer dizer, [...] que a cultura (o simbolismo, as teias de significados, as identidades(...) ou a economia (o trabalho, os processos de produção e circulação de bens) não sejam relevantes ou não estejam contemplados [...]. (SOUZA, 2013, p.88).
}

$\mathrm{Na}$ mesma perspectiva, o pesquisador Saquet (2009), proclama que o território é uma construção social, realizada, portanto, coletivamente e multidimensionalmente. O que não distingue-se, segundo Raffestin (1993, p.

ParaOnde!?, Porto Alegre, v13, n.2, p.196-206, 2020.http://seer.ufrgs.br/paraonde Edição Especial - VII Seminário Internacional de Estudos Fronteriços 
15) das iniciativas territoriais, que excedem as noções de poder diretamente vinculadas a questões políticas, colocando que o território "[...] cristaliza todo um conjunto de fatores, dos quais uns são físicos, outros humanos, econômicos [...], sociais e/ou culturais".

Para Raffestin (1993) todo território resulta em uma demarcação material ou imaterial. No campo concreto, representada pelos limites físicos e definida pelos atores envolvidos e no campo abstrato por meio de representações.

Entretanto, compreender a territorialidade como uma simples ligação com o espaço seria fazer ressurgir um determinismo sem interesse. De qualquer maneira é uma relação, mesmo que diferenciada, com os outros agentes (RAFFESTIN, 1993, p. 161), o que compõe uma crítica às análises que por sorte fixem as territorialidades apenas no campo do físico, considerando-a simplista, observado que as interações com outros agentes, sobretudo, aparentimente ao território, é um componente expressivo em sua estrutura.

A fronteira da qual vamos discutir é a fronteira Brasil-Bolívia ,do município de Corumbá situado no extremo Oeste de Mato Grosso do Sul. Dentro do território brasileiro, Corumbá é um município com aproximadamente 70 mil km2, e mais de 100 mil habitantes, localizada a $410 \mathrm{~km}$ de Campo Grande, capital do Estado de Mato Grosso do Sul, e cerca de $5 \mathrm{~km}$ de Corumbá, no território boliviano que pertence ao Departamento de Santa Cruz, estão situados Puerto Quijarro, pequeno município da Província de Germán Bush, formado por dois distritos - Puerto Quijarro e Arroyo Concepción. Esse espaço fronteriço configura-se como ponto estratégico do principal contato entre bolivianos e brasileiros.

Sabemos que pensar a fronteira, nesta linha imaginária que divide os dois territórios, é pensar em seus contatos, trocas e interações reais, refletindo as especificidades do espaço, que se constitui em uma fronteira diferente em alguns aspectos em relação a outros continentes. A fronteira demarcada e caracterizada por longos desertos, barreiras (naturais ou impostas), postos policiais e corpos rígidos de imigração - como exemplo do americano e do mexicano, não é uma realidade aqui. Conectadas por uma pequena ponte, Corumbá e Puerto Quijarro têm rotinas de mudanças comerciais e populacionais, além da livre circulação de cidadãos e da presença física da polícia federal nos respectivos países.

A força das relações existentes é percebida cotidianamente, seja dentro das casas, onde é comum encontrar famílias constituídas pelas duas nacionalidades, nas escolas, nos centros comerciais e nas manifestações culturais (missas, festas juninas, carnaval, etc.). Para Ernest Guhl (1991) a fronteira alcança diferentes olhares, maneiras e formas, de acordo com a atitude e instância em que se lança o olhar e por quem é lançado. Cada fronteriço sente e vive de maneira diferente, a depender de suas experiências, sempre únicas e exclusivas.

Assim, para entender uma fronteira é preciso interpretá-la não só como um lugar, mas, sim enquanto espaço de vivências, de "tocar" no outro, "sentir"

ParaOnde!?, Porto Alegre, v13, n.2, p.196-206, 2020.http://seer.ufrgs.br/paraonde Edição Especial - VII Seminário Internacional de Estudos Fronteriços 
o outro, de "enxergar" o outro, o que no faz humanos. José de Souza Martins apresenta uma discussão sobre fronteira pautada numa abordagem dos movimentos de expansão da fronteira brasileira, e para o autor a fronteira não se reduz a uma questão unicamente geográfica, mas a entende como: "fronteiras de muitas e diferentes coisas: fronteira da civilização(...), fronteira espacial, fronteira de culturas e visões de mundo, sobretudo, fronteira do humano. " (2009, p.11), Martins ainda ressalta que fronteira é: "lugar de descoberta do outro e de desencontro. Não só o desencontro e o conflito das diferentes concepções de vida e visões de mundo de cada um desses grupos humanos" (2009, p.133).

\section{Identidades territoriais: ser fronteiriço}

Pode-se tratar de diversas maneiras sobre identidade, pois ser de algum lugar, significa pertencer ou se identificar com esse lugar. Quando esse lugar é uma fronteira que apresenta cidades gêmeas,como no caso Corumbá e Puerto Quijarro importa refletir sobre como e em que as relações se estabelecem na construção da identidade fronteiriça de quem vive nesse território.

Compreende-se que primeiramente seja preciso trazer uma definição de identidade. Charles Taylor (1994, p.54) descreve a identidade como "aquilo que nós somos, 'de onde nós provimos'. Deste modo definido como um ambiente no qual os nossos anseios, desejos, opiniões e gostos fazem sentido".

Partimos da premissa de que a construção de identidades (étnicas, culturais, territoriais e sociais, etc.) é um processo que está intrinsecamente ligado a contextos marcados por relações de poder simbólico que, no caso das fronteiras, sejam elas políticas ou econômico- culturais, isso fica ainda mais acentuado. Uma representação social ou um símbolo tem papel fundamental de legitimação à medida que passa a ser conhecida e reconhecida como verdadeira por aqueles que the estão sujeitos ou que a constroem.

Pierre Bourdieu traz um entendimento a cerca desse poder existente:

O poder simbólico é um poder de construção da realidade que tende a estabelecer uma ordem gnosiológica: o sentido imediato do mundo (e, em particular; do mundo social) supõe aquilo que Durkheim chama de conformismo lógico, quer dizer, 'unia concepção homogênea do tempo, do espaço, do número, da causa, que torna possível a concordância entre as inteligências (BOURDIEU, 1996 p.9).

Conforme Tomaz Tadeu Silva (2014), a identidade passa por processos de transformação, de aperfeiçoamento, e desta forma se transforma em dificuldade social, pois o encontro com o "outro" é essencial nesse mundo de diversidades em que se vive hoje. Pensando desta maneira, pode-se compreender que a fronteira deixa de ter uma função negativa, como um obstáculo que não pode ser atravessado, e assume um caráter positivo, de comunicação entre os países vizinhos.

Segundo a autora Reichel (2003, p.281) coloca que os enfoques nos estudos sobre fronteiras têm se ampliado, sendo destacadas as dimensões sociais e culturais, isto porque "esses agentes sociais interagem com a

ParaOnde!?, Porto Alegre, v13, n.2, p.196-206, 2020.http://seer.ufrgs.br/paraonde Edição Especial - VII Seminário Internacional de Estudos Fronteriços 
fronteira e dela se aproveitam para concretizar desejos, reagir a dificuldades, estabelecer contatos, transformando-a em zona fronteiriça" , desta forma demonstra-se que a fronteira funciona mais como uma área de contato e de intercâmbio para os indivíduos que ali habitam e são cotidianamente influenciados por esta relação, do que como uma linha imaginária que divide 0 território pertencente a um e ao outro.

Manuel Castells, traz o conceito de identidade como fonte de significado e de experiência de um povo, é "processo de construção de significado com base em um atributo cultural" (1999, p. 22). Para o autor, as identidades são sempre construídas, utilizando-se de elementos da geografia, da história, de instituições e as memórias coletivas, organizações e aparatos de poder, da religião, que são processados e reinterpretados pelos indivíduos e grupos sociais, construindo seus significados.

O espaço fronteiriço possibilita essas interações, uma vez que o fluxo frequente dos sujeitos dos países aproxima as culturas ao ponto de fazerem contatos fortes e, consequentemente, se misturarem. Mesmo para essa interação, a linguagem reflete a mistura que ocorre entre as culturas e, ao mesmo tempo, é compartilhada pelos falantes das duas nacionalidades, a interação que acontece dentro do intercâmbio social, desempenha um papel fundamental na construção do ser humano, através da relação interpessoal concreta com outros homens.

Para Silva (2014) a identidade está sempre ligada a uma forte separação entre "nós" e "eles". Essa demarcação de fronteiras, essa separação, constrói barreiras humanas nas relações estabelecidas pelos cidadãos fronteiriços reafirmando as relações de poder que toda fronteira carrega consigo.

Ainda Castells (1999, p.21) define identidade como sendo a "fonte de significado e experiência de um povo", nesse sentido a fronteira Brasil-Bolívia ainda está à mercê de uma construção identitária do ser fronteiriço.

\section{Contribuições da literatura na construção do "sentir-se" fronteiriço}

Sabemos que a fronteira nem sempre é vista com "bons olhos", ou como um lugar de conforto, segurança.

Segundo Alves:

[...] A convivência em região de fronteira não é algo que deva ser entendida com simplicidade. O contato que envolve, por um lado a receptividade, a cortesia, o desembaraço e a hospitalidade, por outro oculta a concorrência, a sobrevalorização das diferenças, a busca por uma superioridade idealizada. (ALVES, 2008, P.1).

A fronteira tende a provocar a divisão entre as identidades territoriais, e a literatura atua como instrumento de formação do homem, exprimindo realidades que a ideologia dominante tenta, por vezes, esconder. Para Antônio Cândido (1981) a literatura não corrompe nem edifica, mas tem o poder humanizador em sentido profundo, por que a faz viver.

ParaOnde!?, Porto Alegre, v13, n.2, p.196-206, 2020.http://seer.ufrgs.br/paraonde Edição Especial - VII Seminário Internacional de Estudos Fronteriços 
A literatura é considerada uma das formas mais antigas de difundir cultura e conhecimento da história. Inicia desde o momento em que a raça humana é capaz de processar informações e transmiti-la através da linguagem. A literatura produz conhecimento e sapiência por dar conta de épocas, geografias e estilos de vida que não vivemos, más que permanece interligado com o que somos hoje. Como disse Cândido (1972, p.82), a literatura é uma força humanizadora, que exprime o ser humano e atua em sua formação, ela abre múltiplas interpretações e permite o encontro de si mesmo e do outro, instaurando a linguagem na sua dimensão intensa.

De acordo com o pensamento de Regina Zilberman (2012) em sua obra Teoria da literatura é relativamente difícil ver a literatura como um conceito, em sua forma moderna, o conceito de literatura não surgiu antes do século XVII e não se desenvolveu plenamente até o século XIX. Mas as circunstancias para seu surgimento vinha desenvolvendo desde o Renascimento. A própria palavra começou a ser utilizada em inglês no século XIV, sua raiz foi littera, do latim, uma letra do alfabeto.

Os estudos de Roger Chartier (2001) definem a leitura como uma prática cultural realizada em um espaço intersubjetivo, em que os leitores compartilham dispositivo, atitudes e significados culturais em torno do ato de ler. A literatura é uma linguagem específica que expressa uma determinada experiência humana e dificilmente poderá ser definida com exatidão.

A literatura tem poder de propor especulações ao leitor, incitar a curiosidade, estimular a produção de novos conhecimentos, apropriar-se de uma linguagem rica e variada, facilitando o uso de expressões adequadas para expor ideias e emoções, instruindo o ser humano a interagir no mundo de modo criativo e transformador.

E, além disso, a literatura pode influenciar seus leitores, fazendo-o viver suas histórias e acreditar em suas representações, pois, trata-se de uma:

[..]“linguagem de representação, linguagem imagística, o meio ideal não só para auxiliá-las a desenvolver suas potencialidades naturais, como também para auxiliá-las nas várias etapas de amadurecimento que medeiam entre a infância e a idade adulta" (COELHO, 2000, p.43)

Nesse pensamento de literatura como múltiplas possibilidades de sentir, conhecer a forma de viver, pensar, agir sobre as culturas que circulam nesse território fronteiriço Brasil- Bolívia, Corumbá- Puerto Quijarro e o pensamento de como ver a fronteira e sentir-se parte dela, possibilitam a apropriação de novos conceitos e a partir destes reorganizar sua percepção de mundo, bem como construção de sua identidade. Como assinala Hall: "A identidade é realmente algo formado, ao longo do tempo, através de processos inconscientes, e não algo inato, existente na consciência no momento do nascimento". (Hall, 2003, p. 38).

$\mathrm{Na}$ fronteira, a vida é tecida por relações, e o fortalecimento dessas, deve ser compreendido como uma necessidade no cotidiano. Corumbá tem o viver da cidade fronteiriça, com as multiplicidades dos sentidos de pertença, nesta perspectiva que a literatura é de grande importância para compreensão

ParaOnde!?, Porto Alegre, v13, n.2, p.196-206, 2020.http://seer.ufrgs.br/paraonde Edição Especial - VII Seminário Internacional de Estudos Fronteriços 
da realidade social, pois nela estão as verdades de uma mesma condição humana, o que possibilita ao homem, ao ver seus costumes retratados, uma reavaliação da postura que assume. Ler é criar consciência do que somos, é examinar o mundo em que vivemos para transformá-lo no mundo em que gostaríamos de viver. Zilberman (1990, p. 19) assegura que "o texto literário introduz um universo que, por mais distanciado do cotidiano, leva o leitor a refletir sobre sua rotina e a incorporar novas experiências (...)".

Ainda nos estudos de Cândido (2000), a literatura exerce influência no receptor, o que faz da literatura um instrumento poderoso de mobilização social. A Literatura, por relatar os mais diversos aspectos da vida do homem, torna-se importante aliada na construção da identidade e compreensão da relação que o homem obtém com o espaço.

Abordar a literatura como aproximação de culturas, é expressar o subjetivo do ser fronteiriço, ir além de limites geográficos e diferenças culturais, que são frutos de fluxos constantes dos que as atravessam, para desvendar os personagens, muitas vezes,derivadas de conflitos de classe, e de tensões étnicas presentes no território latino, pois os que vivem na fronteira não partilham somente o território, más sim o pertencimento de culturas e assim o constructo da identidade fronteiriça.

Neste cenário fronteiriço tudo se mistura no movimento do ir e vir diário, que a fronteira traz consigo, como disse o geógrafo Milton Santos: "O conhecimento e o saber se renovam do choque de culturas". Essas relações de partilhas e trocas culturais que acontecem na fronteira oeste Brasil-Bolívia constituem o cotidiano, a literatura não tem o poder de modificar a realidade, mas é capaz de registrá-la e de fazer com que os leitores/fronteiriços reavaliem a própria vida e seus comportamentos, identificando-se com as diferenças e desenvolvendo uma consciência cultural mais ampla. A leitura tem esse papel social, considerando-se que promove a autonomia e contribui para as práticas sociais dos indivíduos. Os leitores interagem com aquilo que lêem e isso faz com que as experiências de leitura evoquem vivências pessoais e proporcionem-Ihes a reflexão sobre a própria identidade, reconstruída da experiência de vivente na fronteira, como afirma Loiva Félix:

"A identidade tem que ser percebida, captada e construída e em permanente transformação, isto é, enquanto processo. Logo, a identidade pressupõe um elo com a história passada e com a memória do grupo" (FELIX, 1998, p. 42).

Além do fato de a literatura tratar com sensibilidade os elementos da realidade de um espaço, ela também contribui para o enriquecimento cultural de povos, desenvolvendo o senso crítico e os suscitando para novas experiências e compreensão da sociedade fronteiriça, a qual estão inseridos. Para Cândido, o diálogo entre a literatura e a sociedade consente perceber que a expressão da diversidade fronteiriça acontece porque:

"Cada sociedade cria as suas manifestações ficcionais, poéticas e dramáticas de acordo com os seus impulsos, as suas crenças, os seus sentimentos, as suas normas, a fim de fortalecer em cada um a presença e atuação deles". (CÂNDIDO, 1995, p.1).

ParaOnde!?, Porto Alegre, v13, n.2, p.196-206, 2020.http://seer.ufrgs.br/paraonde Edição Especial - VII Seminário Internacional de Estudos Fronteriços 
O autor ressalta que $(1995$, p. 37$)$, "a leitura literária permite reflexão sobre o mundo em nossa volta, abrindo horizontes, ampliando conhecimentos", tornando o "ser fronteiriço", compreensivo, crítico e aberto para novos olhares acerca das diversidades encontradas nesse espaço de sentimentos: o lugar, o que inclui raça, gênero, classe social, padrões culturais estabelecidos e linguísticos possibilitando novas perspectivas e acesso aos diferentes saberes. Reflete ainda que a literatura se apresenta como manifestação universal de todos os homens. "Não há povo e não há homem que pode viver sem ela, isto é, sem a possibilidade de entrarem contato com alguma fabulação" (CÂNDIDO, 1995, p.174). Nesse sentido a literatura abre espaço para a alteridade e constituição da subjetividade, possibilitando a troca cultural entre quem habita nesse território fronteiriço. Para Todorov (2009), a realidade que a literatura aspira compreender é "simplesmente[...] a experiência humana" (p.77) e a função primordial da literatura seria permitir que cada "um responda melhor sua vocação de ser humano" (p.24).

\section{Considerações finais}

Á guisa de conclusões, salientamos, aqui, que essas reflexões iniciais, ainda que embrionárias, visam discutir a importância da literatura como função social e aproximadora de culturas. A literatura é a arte que reflete as representações e manifestações da cultura de um povo, percebida como ideal de formação humana, que necessita de um destinatário, um ser concreto, com vivências tão peculiares, próprias de quem circula em um espaço fronteiriço, com olhar produzido por sua própria situação contextual, além da sensibilidade provocadas por situações culturais adversas.

Reconhecer as identidades significa reconhecer suas diferenças em relação ao outro. Em regiões fronteiriças, essas diferenças se tornam mais acentuadas, sendo passíveis de exclusão ou até de preconceitos. A literatura como tem o poder de falar ao coletivo, ela nos aproxima e nos iguala, diminuindo as intransigências existentes em culturas diferentes dentro de uma sociedade e lugar. E as práticas culturais nesse espaço fronteiriço de trocas e vivências compartilhadas, passa a ter mais empatia, pois ao se ver e sentir-se fronteiriço, as diferenças e preconceitos acaba sendo suplantado pelo entendimento que a diversidade faz parte do processo de construção de uma sociedade e respeitar as diferentes formar de pensar e ser que nos tornam humanos.

As contribuições que a literatura, oferece ao ser fronteiriço são múltiplas, proporcionando oportunidades de enriquecer o convívio social entre bolivianos e brasileiros, que vai muito além de trocas comerciais e poder de moedas, mas que estas também ampliam essas relações, como exemplo os fins de semana de Corumbá com grande fluxo de bolivianos em barzinhos, cafés, restaurante, onde os saberes se misturam, as línguas, os costumes, onde o "vizinho" aprecia uma "boa" feijoada ou também tem o prazer de encontrar os pratos típicos de seu país. Talvez essa integração solidifica-se com mais intensidade a partir de incentivos a produções literárias fronteiriças e, dessa forma, a

ParaOnde!?, Porto Alegre, v13, n.2, p.196-206, 2020.http://seer.ufrgs.br/paraonde Edição Especial - VII Seminário Internacional de Estudos Fronteriços 
leitura, enquanto oportunidade de enriquecimento e experiência torna-se primordial na formação do indivíduo e do ser fronteiriço. Pessoas afeitas à leitura, aptas a penetrar os horizontes veiculados em textos mais críticos, são pessoas capazes de melhor desempenho em suas atividades e apresentam melhor aptidão para o enfrentamento dos problemas sociais. Se, por um lado, a leitura pode ser um instrumento de dominação, por outro, é um instrumento de cidadania. $E$, muito embora a leitura não seja o único caminho para a cidadania, ela constrói a cidadania à medida que o homem se constrói dentro dessa sociedade, e para que isso ocorra, faz-se necessário o conhecimento, uma forma de poder e uma fonte de sobrevivência, compreendendo que a literatura amplia conhecimentos e a maneira de entender o mundo que nos circunstância, pois a identidade do ser fronteiriço se constrói a partir das relações humanas.

\section{Referências}

ALVES, E.P. O Professor na Fronteira: Desafios e Possibilidades. Anais do $1^{\circ}$ Seminário Internacional sobre Estudos Fronteiriços. Corumbá/MS. UFMS/CPAN, 2008.

BARTHES, R. Aula: aula inaugural da cadeira de semiologia literária do Colégio de França, pronunciada dia 7 de janeiro de 1977.Tradução de Leyla Perrone-Moisés. São Paulo: Cultrix,2013.

BOURDIEU, P. O poder simbólico. Rio de Janeiro, Bertrand Brasil.1997.

CANDIDO, A. A literatura e a formação do homem. In: Ciência e cultura. SBPC, v.24, n.9, set.1972.

Formação da Literatura Brasileira: Momentos Decisivos. 6 ed. Belo Horizonte: Editora Itatiaia, 1981.

Cidades, 1995.

Vários escritos. $3^{a}$ ed. revista e ampliada. São Paulo: Duas

Literatura e sociedade: estudos de teoria e história literária.

8. ed. São Paulo: Queiroz, 2000.

CASTELLS, M. O poder da identidade. Rio de Janeiro, Paz e Terra.1999.

COELHO, N.N. Literatura Infantil: teoria, análise, didática. São Paulo: Moderna, 2000.

CHARTIER, R. Cultura Escrita, Literatura e História. Porto Alegre: Artmed, 2001.

FÉLIX, L, O. História e memória: a problemática da pesquisa. Passo Fundo: Ediupf, 1998.

GUHL, E. Las fronteras politicas y los limites naturales. Bogotá, Fondo FEN Colombia, 1991.

HALL, S. Da diáspora: identidades e mediações culturais. Org. Liv Sovik.

ParaOnde!?, Porto Alegre, v13, n.2, p.196-206, 2020.http://seer.ufrgs.br/paraonde

Edição Especial - VII Seminário Internacional de Estudos Fronteriços 
Trad. Adelaide La Guardia Resende. Belo Horizonte, MG: UFMG, 2003.

HISSA, C. E. V. A. Mobilidade das fronteiras: inserções da Geografia na crise da modernidade. Belo Horizonte: Ed. da UFMG, 2002.

MARTINS, J. de S. Fronteira: a degradação do Outro nos confins do humano. São Paulo: Contexto, 2009.

NOGUEIRA, R. J. Amazônia Continental: geopolítica e formação das fronteiras. Manaus: Governo do Estado do Amazonas; Secretaria de Estado da Cultura; CCPA, 2007.

RAFESTIN, C. Por uma geografia do poder. São Paulo: Ática, 1993.

REICHEL, H. J. Personagens fronteiriços em tempos de guerra: a região platina (1811-1820). In: Gutiérrez, Horacio; Naxara, Márcia R. C.; Lopes, Maria Aparecida de S. (orgs). Fronteiras: paisagens, personagens, identidades. Franca: UNESP; São Paulo: Olho D’Água, 2003.

SAQUET, M. Abordagens e concepções de território. São Paulo: Expressão Popular, 2007.

SAQUET, M. A. Por uma abordagem Territorial. In: SAQUET, M. A.; SPOSITO, E. S. (Org's.). Territórios e Territorialidades: teorias, Processos e Conflitos. São Paulo: Expressão Popular, 2009. cap.4, p.73-93.

SILVA, T.T. Identidade e diferença: a perspectiva dos estudos culturais. Petrópolis, RJ: Vozes,2014.

SOUZA, M. L. Território e (des) territorialização. In: SOUZA, M. L. Os conceitos fundamentais da pesquisa sócio-espacial. 1. ed. Rio de Janeiro: Bertrand Brasil, 2013. cap. 4, p. 77-110.

TAYLOR, C. Multiculturalismo: examinando a política de reconhecimento. Lisboa: Instituto Piaget, 1994. (p.45-94).

TODOROV, T.T. A literatura em perigo. Trad. Caio Meira. Rio de Janeiro: Difel,2009.

ZILBERMAN, R; SILVA, E, da. (Org.). Literatura e pedagogia: Ponto e Contraponto. Série Confrontos. Porto Alegre: Mercado Aberto, 1990.

Teoria da literatura. $2^{\mathrm{a}}$ ed. Curitiba, PR: IESDE Brasil,2012.

ParaOnde!?, Porto Alegre, v13, n.2, p.196-206, 2020.http://seer.ufrgs.br/paraonde 